\title{
ARTIGO BIBLIOGRÁFICO APÓS A (ANTROPOLOGIA/SOCIOLOGIA DA) RELIGIÃO, O SECULARISMO?
}

\author{
Eduardo Dullo
}

\begin{abstract}
WARNER, Michael; VAN ANTWERPEN, Jonathan \& CALHOUN, Craig (eds.). 2010. Varieties of secularism in a secular age. Cambridge, Mass: Harvard University Press. 337 pp.
\end{abstract}

CALHOUN, Craig; JUERGENSMEYER, Mark \& VAN ANTWERPEN, Jonathan (eds.). 2011. Rethinking secularism. New York: Oxford University Press. 311 pp.

\begin{abstract}
Eu não estou reivindicando algum tipo de teocracia do século XXI. A fé religiosa e seus seguidores não têm a única resposta. Haverá momentos em que políticos e líderes religiosos irão discordar. Mais ainda, o secularismo não é intrinsecamente danoso. Minha preocupação é quando a secularização é forçada a um extremo, quando ela demanda a remoção completa da fé da esfera pública. [...] Eu estou clamando por uma maior confiança na fé, em que a fé tenha um lugar à mesa e não uma posição exclusiva.

Baroness Warsi ${ }^{1}$
\end{abstract}

O texto acima - parte das declarações de Sayeeda Warsi (Chairman do Partido Conservador e primeira muçulmana a ser ministra no Reino Unido) por ocasião de seu encontro, no dia 14 de fevereiro, com o Papa Bento XVI na Santa Sé - demonstra de maneira inquestionável o embate do e com o secularismo no mundo ocidental contemporâneo. ${ }^{2}$ Embora o caso não se desenvolva da mesma maneira em território brasileiro, é possível sentir por aqui semelhanças e reverberações da crise. Seja por meio das polêmicas relativas à legalização do aborto, seja pelas discussões acerca da bancada evangélica, ou ainda pela profusão de best-sellers - como Deus não é grande, de Hitchens, ou Deus, um delírio, de Dawkins - não é fácil dizer que a problemática do que vem sendo chamado de secularismo escapa de nossa vista. Entretanto, o mais provável é que a percepção do conflito tenha motivado a tomada de posição política ao invés de um aprofundamento das pesquisas acadêmicas. ${ }^{3}$ 
Pode-se dizer que, mesmo existindo bons trabalhos desde os anos 1990 (como os de Asad, reunidos em 2003, e o de Connolly, de 1999), foi a partir do portentoso livro de Charles Taylor, A secular age (2007 — já traduzido para o português em 2010), que se expandiu o forte debate a respeito da "era secular" em que vivemos. ${ }^{4}$ Ambiciosamente, Taylor se perguntou: como passamos de uma sociedade em que era virtualmente impossível não crer em Deus (em 1500) para outra (no século XXI) em que a fé e a abertura para o transcendente tornaram-se apenas uma possibilidade dentre outras? Sua resposta centra-se nas transformações das condições de crença e busca da plenitude.

É bastante oportuno observarmos as mudanças teóricas e temáticas através de duas coletâneas: Varieties of secularism in a secular age (doravante Varieties, de 2010) e Rethinking secularism (doravante Rethinking, de 2011). A primeira traz capítulos que pretendem facilitar o acesso do leitor aos argumentos de $A$ secular age, muitas vezes mal interpretados (cf. Introduction, Varieties, 2010:1-31). No conjunto, o livro pretende mostrar a importância da obra de Taylor por meio de duas estratégias: ao debater a dimensão propriamente histórico-filosófica do autor e de seu livro, e ao submetê-lo a fortes críticas que só se tornaram de fato possíveis a partir de sua contribuição. As críticas podem ser agrupadas de acordo com a reivindicação de uma maior atenção aos dados exteriores ao "Atlântico Norte" de Taylor, apresentando a relação com o colonialismo e com outras religiões que não a cristã. Já na segunda coletânea, como nos informa o título, a tarefa é a de "repensar" o secularismo, e isso ocorre de duas maneiras: uma é a continuação do movimento da coletânea anterior, na medida em que os autores utilizam os seus próprios trabalhos para demonstrar a importância desse olhar cuidadoso para além do recorte de Taylor; a outra é a tarefa de busca de novas bases para conceituar e propor um regime secular.

Nos 12 capítulos que compõem a Varieties, discutem-se: as aproximações e os distanciamentos de Taylor em relação a outros/as autores/abordagens, como Jurgen Habermas e Maruyama Masao no texto de Robert Bellah (:32-53); à corrente teológica da Ortodoxia Radical, da qual o próprio John Milbank é membro (:54-82); e a Marx e à sua crítica da religião, por Wendy Brown (:83-104); a importância do Romantismo na análise de Taylor, seu uso da história e sua estratégia narrativa, por Colin Jager (:166-192), Jon Butler (:193-216) e Jonathan Sheenan (:217-242); a retirada de Deus do mundo a partir do Deísmo do século XVIII e sua importância para a consolidação do "enquadramento imanente" [immanent frame ${ }^{5}$ e a mudança na percepção da Natureza, por Akeel Bilgrami (:145-165); Simon During (:105-125) discute a categoria do "mundano" no período neoliberal e as suas implicações 
para a relação com a transcendência de Taylor; William Connolly (:126-144) argumenta sobre uma "ética do devir" e sobre as mudanças nas concepções de tempo e natureza nesse cenário; e, ainda, capítulos sociológica e antropologicamente mais reflexivos e críticos: os de Nilüfer Göle (:253-264), José Casanova (:265-281) e Saba Mahmood (:282-299), que serão utilizados ao longo do ensaio. Por fim, o livro é arrematado com um texto de resposta e consideração do próprio Taylor (:300-321).

A narrativa proposta por ele está restrita ao "mundo do Atlântico Norte" ou "Cristandade Latina" e diferencia três sentidos de "secularidade". O primeiro (Secularity 1) compreende as instituições sociais e políticas e a separação formal e legal destas e da religião institucionalizada - aqui, a religião se torna assunto privado. O segundo sentido (Secularity 2) abarca o declínio da frequência ao culto e a diminuição na proporção de fiéis autodeclarados. Porém, o sentido que realmente interessa a Taylor é o terceiro (Secularity 3), e envolve a mudança nas condições da crença: "secularidade nesse sentido é uma situação de todo o contexto de entendimento, no qual nossa experiência religiosa, espiritual ou moral toma lugar" (Taylor 2007:3). Para ele, todos nós (sejamos "religiosos" ou não) buscamos a plenitude [fullness] ${ }_{1}^{6}$ ainda que não a entendamos da mesma maneira: "secularidade é uma condição na qual nossa experiência e busca da plenitude ocorrem; e isso é algo que todos nós compartilhamos, tanto os crentes quanto os não crentes" (2007:19). A noção de experiência é central na argumentação, pois é a partir das maneiras pelas quais nos esforçamos para achar sentido nelas e por nossa procura de plenitude que se centra a discussão. No cenário religioso há a busca por melhoramento do ser humano, mas condicionado a um bem maior: a glória de Deus; na era secular admite-se o humanismo autossuficiente e a procura deixa de ter um referencial no transcendente, centrando-se nesse mundo e em sua própria capacidade de agir.

A partir destas informações já é possível notar que Taylor não nega a existência da secularização, mas busca compreendê-la em profundidade, nuançando algumas de suas proposições. Assim, questiona as teorias da secularização pelo que chamou de "Narrativa da Subtração" e propõe a sua narrativa:

Na narrativa da subtração não pode haver perda epistêmica envolvida na transição do encantamento para o desencantamento; nós só sacudimos algumas falsas crenças, medos sem concretude e objetos imaginados. Visto do meu modo, o processo de desencantamento envolve uma mudança na sensibilidade; a pessoa está aberta para coisas diferentes e, ainda, perdeu um modo importante pelo qual as pessoas costumavam ter experiências no mundo (Taylor in Rethinking 2011:39). 
Como (re)afirmam os editores de Varieties (2010:24-25), os secularistas que subscrevem a narrativa da subtração naturalizam aquilo que eles mesmos produziram: as sociedades seculares não são "a humanidade menos a religião", mas uma condição singularmente moderna do ser social, alcançada historicamente. Esta mudança na análise envolve a recuperação do termo "secular" e, principalmente, das transformações sofridas ao longo dos últimos séculos:

[O secular] começa como um termo em uma díade que distingue duas dimensões da existência, identificando-as pelo tipo particular de tempo que é essencial a cada. Mas da fundação dessa clara distinção entre o imanente e o transcendente se desenvolve outra díade, na qual "secular" refere-se àquilo que pertence a uma esfera imanente, autossuficiente, e é contrastado com aquilo que pode, então, passar por uma nova mutação, por meio da negação do nível transcendente, sendo aquilo que é meramente inventado ("religioso"); ou onde "secular" se refere às instituições de que nós realmente precisamos para viver "nesse mundo", e "religioso" ou "eclesial" se refere aos acessórios opcionais que, com frequência, perturbam o curso da vida nesse mundo (Taylor in Rethinking 2011:34).

O "secular" aparece primeiro como uma temporalidade contraposta ao tempo escatológico (cf. Casanova in Rethinking 2011:56). Uma conferência de Koselleck (2003) é particularmente instrutiva: ali, ele contrasta a aceleração do tempo cristã, em que os anos se tornam dias por ocasião da parousia, com a aceleração "secular" promovida pela indústria e relatada em 1886 por Siemens, empresário e engenheiro elétrico. A modificação central para Taylor é quando deixa de se referir a uma temporalidade ("a oposição entre passado e futuro passa a ocupar o lugar central, afastando a oposição entre o mais próximo e o mais distante" [Koselleck 2003:46]) e o "secular" passa a se opor à noção de transcendente, assumindo o sentido daquilo que é imanente, aquilo que é feito pelo homem sem intervenção divina. Por fim, passa-se ao momento em que o transcendente é negado como realidade, desfazendo a oposição e assumindo a "religião" como uma ação humana: é o homem que, não esclarecido, preso a superstições, cria a "religião".

Há mais de uma oposição em jogo e faremos bem em distingui-las. Por um lado, temos a imanência versus transcendência; por outro, profano versus sagrado e, por fim, secular versus religioso. Os termos podem ser combinados: o secular pode ser sagrado, como nas análises: 1. dos Direitos Humanos feita por Asad (2003), 2. do Estado-nação "quase religioso" (Milbank in Varieties 2010:75-76), e 3. do culto do indivíduo (Casanova in Rethinking 2011:65; cf. Duarte 1983), entre outras. 
Com isso, a temática da "secularização" foi remodelada e expandida em três frentes: a secularização propriamente dita passou a ser descrita não apenas como um processo, mas também como um projeto sociopolítico inacabado; o secularismo, por outro lado, é a doutrina política que sustenta o mundo secular e que se opõe à religião, sendo descrita por uns como uma ideologia e, por outros, como uma visão de mundo - como evidencia o trecho de Warsi, em epígrafe; o secular, por fim, é analisado como uma categoria epistêmica propriamente moderna, que se afirma como uma "realidade natural desprovida de religião, como o substrato antropológico e social natural que permanece quando o religioso é retirado ou desaparece" (José Casanova in Rethinking 2011:55; cf. Asad 2003:191).

Casanova utiliza, ainda, dois termos distintos (secularização e laicização) para processos que ele considera, respectivamente, Protestante e Católico (Varieties 2010:276). Porém, mais que restringir os processos a vertentes cristãs específicas, cabe ao pesquisador observar a diferenciação como modelos. No caso da "secularização", Casanova clama por seu conceito teológico "original", de transformação do binarismo, ao insuflar o religioso no mundo, isto é, "traz do monastério para o mundo secular a vida religiosa de perfeição" (Casanova in Rethinking 2011:56). Já a "laicização" seria o caminho mais comum nos países católicos da Cristandade Latina, em que o antagonismo laico/clerical é mais rígido e a oposição entre religioso/civil se fez mais forte junto ao anticlericalismo, empurrando a religião para as margens da sociedade e rumo a uma maior privatização - tendo o caso francês e sua laicité como paradigmático (Rethinking 2011:57).

Com tantas mudanças no polo antagônico do "religioso", os autores discutem, também, o próprio conceito de "religião". Levanta-se a história do conceito nos estudos de religião comparada, como em Jonathan Smith (2004), observando a condição moderna da categoria, a delimitação da religião como crença e sua circunscrição ao domínio privado simultaneamente ao estabelecimento do "secular" como resíduo natural. Asad é um crítico deste conceito de religião, tendo se manifestado a respeito da definição universalista de Geertz (Asad 2010 [1983]) e, posteriormente, a respeito do livro de W. C. Smith (Asad 2001). Sua posição é a de um antiessencialismo, optando por definições situadas de acordo com os regimes discursivos históricos que constituem o termo, isto é, não se trata de buscar uma melhor definição, já que a própria definição deve ser observada situacionalmente. Taylor, por outro lado, não tem a mesma posição e tem a ousadia de definir o que entende por religião: esta se ancoraria na oposição imanente/transcendente, uma definição que, como ele reconhece, é feita sob medida para a "nossa cultura" da Cristandade Latina (2007:15-16). 
Voltemos, portanto, às coletâneas. Ainda que circunscrito aos problemas levantados por Taylor, o volume traz a marca do pluralismo: Varieties é uma referência ao livro de William James - The varieties of religious experience (2007 [1902]). Colocam-se em questão, assim, as razões para se utilizar o singular ao falar de secular/secularismo/secularização. Serão o mesmo processo e o mesmo projeto sociopolítico em toda parte ou existirá uma ampla variedade de secularismos? Será que, assim como a variedade da espécie "religião"7 nos permitiu abarcar o cristianismo, o budismo, o islamismo, o judaísmo, o hinduísmo e outras tantas, existe também uma variedade da espécie "secularismo" que passa pelo caso dos Estados Unidos, da Turquia, da China, da França, da

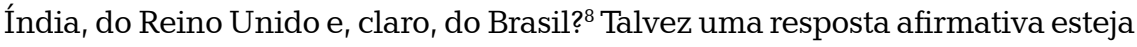
no uso dos termos em inglês secular e secularism e na manutenção de laicité para menções ao caso francês, destacando-o como um fenômeno singular e extremado de secularismo ao invés de vê-lo normativamente.

Dentre os capítulos reunidos, o texto de Nilüfer Göle em Varieties (:243-264) procede a uma breve comparação entre a laicité francesa e a laiklik turca. A sua crítica central é a de que uma leitura introspectiva da secularidade ocidental, ainda que não seja etnocêntrica, perde facilmente de vista os poderes culturais do secular. Com a pergunta "como a experiência muçulmana da secularidade transforma e questiona nosso entendimento da era secular?" (:245), sua crítica faz uso de uma dimensão atual do conflito encarado pelo secularismo francês: os migrantes muçulmanos e, mais ainda, a entrada das mulheres, com suas vestes distintivas, no espaço público.

Na percepção da república francesa, as características étnicas, religiosas e de classe são neutralizadas na figura do cidadão. Assim, as muçulmanas trazem não somente a religião, mas também o gênero e o colonialismo, demonstrando a presença dos migrantes do norte da África. A proibição do uso do véu é vista como a afirmação de uma única maneira possível de ser indivíduo, caso se queira a integração na nação (Varieties 2010:251).

Quando aborda a laiklik turca (como um exemplo da referida expansão do Ocidente), Göle enfatiza o caráter de "missão civilizadora" operante no nível cotidiano e como o "secular moderno é "indigenizado" e desempenhado para mudar as definições muçulmanas de "self, ética e estética" (:253). A postura turca é a de um Estado republicano em que a religião está ausente e as mulheres presentes na esfera pública. Porém, as mulheres que aparecem na esfera pública com sinais religiosos praticam, em sua análise, uma dupla transgressão: sendo piedosamente públicas, elas não obedecem nem aos ditames seculares nem aos da reclusão das mulheres no espaço privado, submetidas às interpretações masculinas dos preceitos islâmicos (Varieties 2010:254-259). 
Se a crítica de Göle apresenta a entrada da alteridade no Ocidente, ausente na narrativa de Taylor, com Casanova (Varieties 2010:277) argumenta-se como a globalização da secularização ocidental cristã foi, para muitos, concretizada pela empreitada colonial. Ou, como colocam os editores de Varieties (:27): "o processo pelo qual a Cristandade Latina tornou-se secular foi, em grande parte, o mesmo processo pelo qual ela se tornou colonial". Esta questão é desenvolvida por Mahmood (Varieties 2010:282-299), que não apenas critica a narrativa de Taylor por deixar de fora tudo o que não é a Cristandade Latina, como também chama a atenção para as transformações operadas no próprio Cristianismo a partir dessa relação com os povos colonizados. Foi, em parte, com os missionários que se desenvolveu o próprio conceito moderno de "religião" e na expansão das escolas entre os povos colonizados (sejam elas de missionários ou do Estado) que se experimentaram técnicas que foram, posteriormente, adotadas nos países europeus (:286-288). Mais ainda, coloca em dúvida a narrativa por privilegiar o secular a partir do Cristianismo, numa sugestão de autoridade universalizante em face de outras experiências do secular - lembrando, com isso, a posição hierarquicamente superior do Cristianismo na própria definição da variedade "religião" (Mahmood in Varieties 2010:289-294; cf. Smith 2004:190).

Em Rethinking secularism esta problemática ganha novos contornos: discute-se menos o livro de Taylor e centra-se mais nos trabalhos dos próprios autores, isto é, ocorre uma verdadeira discussão a respeito da oposição religioso/secular para além do espaço restritivo do "Atlântico Norte", como reivindicou Casanova em sua preocupação com a globalização: "enquanto o sistema de classificação da realidade religioso/secular pode ter se globalizado, o que permanece bastante disputado e debatido em quase todo lugar, hoje, no mundo, é como, onde e por quem as fronteiras entre o religioso e o secular podem ser desenhadas com propriedade" (Rethinking 201:63). Assim, Rajeev Bhargava (:92-113), utilizando a experiência indiana, apresenta sugestões para reabilitar o secularismo em outras bases, enquanto nos capítulos de Richard Madsen (:248-269) e Peter Van der Veer (:270-281), vemos o seu avanço e a sua relação com as tradições culturais e/ou religiosas locais. O primeiro, a partir da China, onde o "Estado tentou suprimir e dominar totalmente a religião"; da Indonésia, "onde o Estado tentou cooptar as religiões para um regime corporativista"; e de Taiwan, em que o Estado "tentou uma mistura de supressão e cooptação, mas, por fim, moveu-se para a tolerância liberal" (:257). O segundo pela comparação do secularismo na Índia e na China não apenas como processo, mas como projeto.

Um dado importante são as definições estatais de religião: na China, são apenas cinco as reconhecidas e o governo clama para si a autoridade 
de distinguir uma "verdadeira religião" de um "culto maléfico". Madsen afirma existir uma diferença entre a face que se apresenta e a face interna: enquanto internacionalmente a China parece secular, para seus cidadãos há fortes conexões entre o governo e forças cósmicas (Madsen in Rethinking 2011:250). Uma de suas conclusões é a de que as tentativas estatais de suprimir a religião não terminaram com a presença dela na sociedade, nem a privatizaram, ainda que os Estados se afirmem seculares. Outra conclusão importante é que nas sociedades asiáticas o imanente e o transcendente estão muito mais misturados e em combinações híbridas (:266).

Já na análise de Van der Veer, em que pesem todas as diferenças, ambos os projetos estão articulados com a empreitada colonial. No caso da Índia, a luta anticolonial adquire características e reivindicações a partir das tradições religiosas locais (:278-280). O capítulo de Mark Juergensmeyer (:185203) discute a violência tanto de ativistas religiosos quanto de seculares, apontando para a percepção dos primeiros de que o Estado secular é um inimigo, já que incapaz de protegê-los e, ainda mais, por marginalizá-los. Assim, discute-se a própria ideia desses ativistas de que há algo chamado "religião" que está excluído da vida pública. Juergensmeyer observa que a época de ouro do Nacionalismo Secular (1945 a 1990) foi sustentada pela elite urbana, na pretensão de afastar-se de identidades paroquiais do passado. Essa postura tentava ultrapassar as alianças religiosas locais pelo fomento de um nacionalismo suprarreligioso ou antireligioso (:191). Porém, após esse período, o secularismo entrou em crise, em parte por sua associação com o imperialismo colonial. Nos países não ocidentais, ele argumenta, não ocorreu a privatização da religião e seu confinamento no domínio da crença: ela opera como marcador de identidade coletiva, virtudes públicas e preocupações cidadãs com a sociedade (:193). A disputa entre o nacionalismo secular e o religioso é pela autoridade de afirmar-se como a base moral da sociedade e definir quando um ato violento é legítimo ou não (:196).

Isto nos leva ao texto de Elizabeth Shakman Hurd (:166-184), em que ela questiona a naturalidade da díade secular/religioso nas teorias de Relações Internacionais. Sendo a religião privada, não haveria espaço para ela nas análises das disputas entre Estados. Entretanto, os fatos não corroboram essa posição. Com a crescente "guerra ao terror", tanto os países com grande população muçulmana quanto os Estados Unidos têm se articulado para impedir a presença religiosa na política e consolidar regimes secularistas. Fica evidente sua preocupação analítica com a instabilidade da díade ao menor sinal de interações entre esses atores, instabilidade visibilizada tanto no Irã quanto na Turquia pela repressão não democrática dos regimes seculares. 
Alfred Stepan (:114-144) argumenta, a partir de dados de diversos países e traçando tipologias, como a secularidade não afeta, necessariamente, a condição democrática. Já Craig Calhoun, em seu capítulo (:75-91), contesta a normatividade da cidadania secularista, que opera uma irônica exclusão ao afirmar a secularidade como condição de participação igualitária — dos sujeitos religiosos e de suas falas que não seguem o enquadramento imanente autossuficiente, e beneficia uma classe média secular, uma maioria "nativa" na Europa e a elite branca nos Estados Unidos em detrimento de negros, latinos e imigrantes mais religiosos. Assim, discutindo com os trabalhos recentes de Rawls, Habermas e Taylor, questiona o aceite dos argumentos religiosos desde que sejam traduzíveis para justificativas propriamente políticas, pois uma clara divisão entre crenças seculares e religiosas só é viável para os não religiosos (:82).

Um exemplo da problemática pode ser visto no capítulo de Asad em Rethinking (:282-297), ao discutir a liberdade de expressão secular e a categoria blasfêmia a partir das charges publicadas em jornal da Dinamarca. Ali, vemos as contradições levantadas pela bandeira da liberdade e de livre escolha diante da sedução discursiva do mercado e do direito de propriedade (autoral e intelectual). Talvez um dos problemas seja a concepção moderna de religião que coloca a crença como sua característica central. É por isso que é tão relevante a crítica de Asad (2012) a Taylor (cf. Rethinking 2011:40), (re)afirmando a importância dos sentidos e das práticas.

E quais as conclusões desse debate? Não seria a discussão muito similar a diversas outras que são feitas a respeito da "Modernidade", do estatuto da "Religião" no mundo contemporâneo e da noção de "Pessoa" articulada sob essas rubricas ${ }^{9}$ Sim, de fato, é bastante similar. Basta observar a trajetória de Taylor com seu já clássico "As fontes do Self" — ou a de Asad — com pesquisas sobre agência, corpo $(2003,2011)$ e a categoria de religião $(2001,2010)$.

Mas se há continuidade de certas linhas de pesquisa, há também importantes modificações. Uma delas é o aprofundamento teórico das próprias noções que orientam o debate. Saímos da laicidade e sua ascendência francesa para entendermos a diferença entre o secular e o laico. Outra é a perspectiva comparada permitida pela reunião do trabalho de diversos pesquisadores sob uma rubrica. Porém, a mais central é a percepção crítica a respeito da neutralidade e da naturalidade sustentadas por teorias acadêmicas a respeito da secularidade de nossa época: não mais a assunção de uma narrativa da subtração da religião geradora de uma percepção do imanente e do mundano como o resíduo intacto, racional e desejado, mas uma verdadeira pesquisa e análise das formas pelas quais se construiu este mundano imanente a partir da situação sócio-histórica local, em conflito ou em relativo consenso, de acordo com a "religião" e as tradições religiosas. 
Desta maneira podemos depreender que a própria equação de "modernidade" com "secular" é o alvo da crítica, ou seja, a argumentação de alguns desses autores parte da constatação da existência de agentes modernos e religiosos, ou melhor, quanto mais modernos eles se fazem, mais religiosos eles ficam. Ou, como afirmou Regui ao Le Monde após uma mesa redonda que discutia a radicalidade da laicité contemporânea: "Há séculos, ao mesmo tempo que praticantes, os judeus contribuíam com todos os desenvolvimentos tecnológicos e científicos. Não há nenhuma contradição entre nossa prática religiosa, nossa cidadania e nossa contribuição à modernidade". ${ }^{10}$ A fala deste judeu francês, bem como a da muçulmana britânica (em epígrafe) nos fazem pensar que, talvez, não seja apenas para as ex-colônias, fora da Europa, que as críticas tenham pertinência. É assim que a proposta de uma "antropologia do secularismo" ou das "formações do secular" reivindica a positividade que não fica explícita nas rubricas anteriores e que se concretiza na comparação de casos nacionais e de diferentes religiões.

Recebido em 21 de março de 2012

Aprovado em 24 e agosto de 2012

Eduardo Dullo é doutorando em Antropologia Social no Programa de Pós-Graduação em Antropologia Social, Museu Nacional, UFRJ. E-mail: <edudullo@gmail.com>

\section{Notas}

${ }^{1}$ Disponível em: http://www.telegraph.co.uk/news/politics/9080452/Britainbeing-overtaken-by-militant-secularists-says-Baroness-Warsi.html. Acessado em: 13/02/2012. Todas as traduções são de minha responsabilidade.

${ }^{2}$ Após as pronunciações de Warsi, seguiram-se apaixonadas manifestações na imprensa britânica, pró e contra. Para um sumário de diversas opiniões - a partir da posição secularista de seu presidente - ver http://www.secularism.org. uk/blog/2012/02/the-great-debate-begins. Acessado em: 23/02/2012. E o site oficial http://sayeedawarsi.com/.

${ }^{3}$ Uma das poucas teses brasileiras sobre o fenômeno do secularismo é a de Gordon (2011), ainda que sua argumentação não seja caudatária desse debate. 
${ }^{4}$ Cannell (2010) explora as perspectivas de Asad, Mahmood e Hirschkind, e as oriundas da experiência indiana. Entretanto, só o faz a partir do debate gerado por A secular age.

${ }^{5} \mathrm{O}$ "enquadramento imanente" organiza a experiência no mundo secular descrito por Taylor, sendo o título do capítulo 15 de A secular age. É em referência a ele que surgiu o blog coletivo, hospedado pelo Social Science Research Council, http://blogs.ssrc.org/tif.

${ }^{6}$ Esta é uma posição de Taylor, pouco ou nada compartilhada por outros autores. Asad, por exemplo, preza um antiessencialismo.

${ }^{7}$ Para uma análise da expansão do conceito, ver Asad (2001) e Smith (2004).

${ }^{8}$ A preocupação com a secularização como projeto sociopolítico e com a "Secularidade 1" de Taylor faz pensar nas maneiras pelas quais os diferentes Estados regularam a religião e a liberdade religiosa em seu território. Já a "Secularidade 3" ultrapassa fronteiras e sua expansão para além do mundo do Atlântico Norte sofrerá críticas.

${ }^{9}$ Giumbelli (2011:38-341) apresenta questionamentos nessa direção, a partir da proposta de Asad. Seu texto envolve algumas das considerações do presente debate, como a definição moderna de "religião" e a preeminência adquirida pela noção subjetivista de "crença". Porém, se mantivermos a ideia (cf. p. 348-349) de que a liberdade de crença vem associada à de não crer, perceberemos que a proposta de uma antropologia do secularismo questiona: o que se diz, ao falar que não se crê? Como se constitui o sujeito que não crê? Vemos aí a ausência deixada pelo declínio da religião criticada por Taylor: tudo que sobrou foi a "razão", natural ao humano, isto é, alguém que não crê é alguém liberto "'das crenças absurdas' pela nossa corajosa e ambiciosa modernização" (Latour apud Giumbelli 2011:347). A pergunta também é feita, retoricamente, por Hirschkind (2011).

${ }^{10}$ Disponível em: http://www.lemonde.fr/societe/article/2012/03/17/si-la-laicitese-durcit-et-se-radicalise-les-juifs-seront-les-grands-perdants_1671398_3224.html. Acessado em: 20/03/2012 


\section{Referências bibliográficas}

ASAD, Talal. 2001. "Reading a modern classic: W. C. Smith's The meaning and end of religion". History of Religions, 40(3):205-222.

- 2003. Formations of the secular: Christianity, Islam, modernity. Stanford: Stanford University Press.

. 2010 [1983]. "A construção da religião como uma categoria antropológica". Cadernos de Campo, 19:263-284.

_ 2011 [2003]. "Reflexões sobre crueldade e tortura". Pensata. Revista dos Alunos do Programa de Pós-Graduação em Ciências Sociais da UNIFESP, 1(1):164-187.

- 2012. "Thinking about religion, belief and politics". In: Robert Orsi (ed.), The Cambridge Companion to religious studies. Cambridge: Cambridge University Press. pp. 36-57.

CANNELL, Fenella. 2010. "Anthropology of secularism". Annual Review of Anthropology, 39:85-100.

CONNOLLY, William. 1999. Why I am not a secularist. Mineapolis: University of Minnesota Press.

DUARTE, Luiz Fernando Dias. 1983. "O culto do eu no templo da razão (três ensaios sobre pessoa e modernidade)". Boletim Museu Nacional, 41:2-27.

GIUMBELLI, Emerson. 2011. "A noção de crença e suas implicações para a modernidade: um diálogo imaginado entre Bruno Latour e Talal Asad". Horizontes Antropológicos, 35:327-356.

GORDON, Flávio. 2011. A cidade dos Brights: religião, política e ciência no Movimento Neo-Ateísta. Tese de Doutorado, PPGAS/Museu Nacional/UFRJ.

HIRSCHKIND, Charles. 2011. "Is there a secular body?" Cultural Anthropology, 26(4):633-647.
JAMES, William. 2007 [1902]. The varieties of religious experiences. Radford: Wilder Publications.

KOSELLECK, Reinhard. 2003. Aceleración, prognosis y secularización. Valencia: Pre-Textos.

SMITH, Jonathan Z. 2004. "Religion, religions, religious". Relating religion: essays in the study of religion. Chicago: The University of Chicago Press.

TAYLOR, Charles. 2007. A secular age. Cambridge, Mass: Harvard University Press. -2010. Uma era secular. São Leopoldo: Unisinos Editora. 


\section{Resumo}

O presente ensaio apresenta ao público brasileiro, a partir de duas coletâneas Varieties of secularism in a secular age (2010) e Rethinking secularism (2011) o recente debate sobre o secularismo. Os diversos autores pretendem seguir a crítica de Charles Taylor em A secular age (2007), em que questiona a tese da retração da religião das diversas esferas sociais sem que as mesmas sofram profundas alterações, isto é, ignorando seu caráter relacional. O principal argumento mobilizado é, nesse sentido, a necessidade de reavaliar a dicotomia secular/religioso, compreendendo a mútua constituição dos polos, bem como o efeito desta dicotomia em países fora do "mundo do Atlântico Norte", de tradição judaico-cristã. Diferencia-se, assim, "secularização", "secularismo" e "secular" como três fenômenos relacionados, mas não homogêneos. A proposta subjacente, de pesquisas sobre a "formação do secular", reivindica, portanto, uma análise da positividade do secular ao invés da simples ausência do religioso.

Palavras-chave Religião, Secularismo, Talal Asad, José Casanova, Charles Taylor.

\section{Abstract}

This paper introduces the Brazilian public to the recent debate on secularism, drawing upon two collections - Varieties of secularism in a secular age (2010) and Rethinking secularism (2011).The various authors contributing to these works intend to pursue the critique Charles Taylor makes in A Secular Age (2007), which questions the thesis of that religion can withdraw from social spheres without causing profound changes, i.e. a thesis which ignores the relational character that exists between religion and these spheres. The main argument mobilized is, accordingly, the need to reevaluate the secular / religious dichotomy, through a better understanding of the mutual constitution of both poles, as well as the effect of this dichotomy in countries outside of the "North Atlantic world" and the Judeo-Christian tradition. "Secularization", "secularism" and "secular" are thus differentiated as three related, but not homogeneous, phenomena. The underlying proposal, which calls for research into the "formation of the secular", seeks to study secular positivity, rather than the simple absence of religion.

Key words Religion, Secularism, Talal Asad, José Casanova, Charles Taylor. 